\title{
Coping Strategies of Power Supply Limitations as Predictors of Informal Sector Productivity in Offa, South West Nigeria
}

\author{
Onawola, M.O. \& Lawal, A.K. PhD \\ Department of Business Administration \\ National Open University of Nigeria \\ Offa Study Centre \\ Offa, Kwara State, Nigeria
}

\begin{abstract}
This study developed a research instrument to gather primary data on the coping strategies of power dependant informal sector in Offa, South Western, Nigeria. economy. This to determine how power affect productivity of informal sector, the challenges faced by the sector and the coping strategies used in coping with the challenges. The study use simple random sampling techniques for the subject and data collection were achieved through the use of questionnaire, personal interviewed and information gathered from journals and website. The questionnaire were designed to be answered by the productive artisan group in the sampled community which comprises the Iron welding or fabricating, the sachet and bottle water and the milk and fruit plant. The data collected was processed and analysed using Microsoft excel. This work revealed that basically informal sector depends on power for production; however the power supply is not adequate for the required consumption. The study revealed that $66 \%$ majority of respondent are of opinion power supply was very bad and not reliable for the use in production process, which makes them results in alternative use and $96 \%$ of respondent results in use of generator as alternative which is very expensive that affect their productivity negatively. The study revealed $98 \%$ of respondent agreed that if power supply was stable and reliable is the best source of electricity for efficient productivity of informal sector. The researcher proposed that the government should urgently address the major challenges facing the informal sector which is the epileptic power supply among others and by addressing the problem that affects the output of power sectors to enhance good service delivery their by improving the productivity of informal sectors.
\end{abstract}

Keywords: Informal sector, power, recession, economy, coping strategies and productivity

Aims Research Journal Reference Format:

Onawola, M.O. \& Lawal, A.K. (2019 Coping Strategies of Power Supply Limitations as Predictors of Informal Sector Productivity in Offa, South West Nigeria. Advances in Multidisciplinary Research Journal. Vol. 5. No. 1, Pp 97-116 Article DOI: dx.doi.org/10.22624/AIMS/V5N1P10

\section{INTRODUCTION}

The contribution of the informal sector to growth of the Nigerian economy is quite significant. The informal sector is better placed to absorb unutilised resources which the public sector and the organised private sector are not willing or able to use. Moreover, through linkages with large-scale enterprises, informal sector enterprises have the production base of the economy. The informal sector contributes significantly to national economy in terms of output and employment. The informal sector in Offa community contribute to the growth and development of the town. The economy contribution like promoting growth, employment generation, poverty alleviation.

Despite the contribution of informal sector to development there are still so many obstacles that limit the survival of informal sector. These obstacles include handicap in obtaining finance, poor management practice, low demand for product and services, low entrepreneur skill, shortage of raw material, over bearing regulatory and operational environment, unfavourable tariff policy and poor infrastructure or infrastructure deficiency such as power supply problems. Power supply problems could be epileptic power supply or in adequate power supply or power outages. Among obstacles that limit the survival of informal sector or that limit the productivity of informal sector, the one to be discuss in this study is the power supply. 
This study is set to examine this power dependent sector or entrepreneurs, the power dependant could be divided into sections:

$$
\begin{aligned}
& >\text { Manufacturing } \\
& >\text { Servicing } \\
& >\text { Processing }
\end{aligned}
$$

The informal sectors plays significance role in the economy development. Despite the roles the informal sector plays in the economy development the sector still faces or encounter a lot of problem in surviving. Most informal sector die within the first five years of existence, a smaller percentage goes into extinction within sixth to tenth years while only about five to ten percent survive, thrive and grow to maturity. A lot of factors have been identified contributing to this premature death of informal sectors. The key among others include: insufficient capital, irregular power supply, infrastructural inadequacies, lack of focus, over concentration on one or two for finished product, lack of business strategies and epileptic power or inadequate power supply. However there are a lot of factors that affect the performance or productivity of informal sectors but the poor state of power supply in the country is one or major significant factor militating against the performance of informal sector.

\section{RELATED WORKS}

Emmanuel (2016) submitted that impact of power supply failure on the economy growth cannot be over emphasized, starting from its effect on household, industry and the economy at large. The equality and quantity of a country's power supply determine its ability to create competitive sector. Since the performance of informal sector is greatly influenced by the power supply. Given the pathetic state of power supply in the country it is no wonder that the contribution of the development of people, manufacturing sector and the economy in general is very negligible or unsupported by the government.

Nigeria has abundant power supply energy sources. It is endowed with thermal, hydro, solar and oil resources but still it is describe as an energy poor country because the sector is relatively underdeveloped. Previous Statistics have shown that only about one third of Nigerian or approximately 40 percent of the population have access to electricity. The distribution of electricity shows great disparities between rural and urban, and between residential and industrials areas in the urban centres [Ali-Akpajika and Pyke 2003].

The sun newspaper [March 20016] It was quoted that the poor power situation in the country was no longer a laughing matter. The president MAN; president Frank jobs also send the ripple effects of the power shortages and constant outages were numerous ranging from cut down in production, job loss to outright closure or relocation to other countries by industries. He added that companies had to bear so much loss as the outage occurs when goods are in middle of production. With view of these if large sectors could feel the impact like these it means informal sectors are at the receiving end with regards to power outages. Artisans running business such as welding and steel fabrication, aluminium, hair dressing saloon, frozen foods, sachet and table water factory, fruit and milk juice plant hardly survive without adequate power supply. All this and how the informal sector are coping in the recessed economy led the researcher interest in this concept.

\subsection{Research Focus}

The researcher area of study is the manufacturing or producing sectors. These sector could be iron steel welding and fabricating, bakery, blocks and concrete poles, sachet or bottle water factories. Inadequate power supply constitutes one the greatest constraints in informal sector development. Power is generally known for its unreliability and epileptic supply. A journal by KPMG Nigeria 2016. Power remains the principal catalyst for transforming Nigeria industrial and commercial landscape, power is the major determinant in productivity. Electricity generation in the country started in Lagos 1896 some 15 years after that of Britain from which Nigeria obtained independence in 1960. In the northern part it is the Nigeria Electricity supply company (NESCO) began operation in 1929 as an electric utility company in Nigeria with the construction of a hydroelectric power station at Kura near Jos. 
The coordination of the supply and development of electricity occurred in 1951 with establishment of Electricity Corporation of Nigeria (ECN). The Niger Dams authority (NDA) establish in 1962 and ECN and NDA were merge in 1972 to form the National Electric Power Authority a company with electricity generation, transmission, distribution and Sales throughout the country. Despite its long history NEPA development is very slow and in spite of various effort to manage the sector and provide good electricity, it is clear Nigeria electricity system was failing to meet Nigeria power needs. Power firms was faced with different operational challenges like power theft, Lack of maintenance culture, Lack of proper Financing scheme, Lack of infrastructure. All these leads to inadequate supply for the informal sector that depend majorly on power for survival and productivity.

\section{RESEARCH DESIGN}

\subsection{Area of Study}

The study covers the Artisanal sectors in Offa community area in Kwara state. The artisanal activities in the community could be categorised into the following sub-sectors:-
1. Productive
2. Service
3. Financial

The selected sectors in the research work are basically the productive sub sector that depends on power usage for their production. In this study the specific focus of productive sectors are Iron welding and fabricating, sachet and table water plants, milk and fruit juice plant.

\subsection{Sources of Data}

The data used for this study was obtained from different sources. Data were gathered from the use of questionnaire, personal interviewed and information gathered from journals, website and some data that already collated by previous researcher. The data were sourced from both primary and secondary data. The primary source was derive from respondents via questionnaire and personal interviewed. While the secondary data were derived from journals, website, those data which have already been collated and analysed by previous researcher in analysing the results obtain through primary source after taking cognizance of purpose and objective of study.

The primary sources of data use were questionnaire and personal interview with some respondents:

Questionnaire: This is the researcher major source of primary data used. The data obtained through the questionnaire constructed by researcher and as approved by supervisor. The questionnaire was share within the owners or managers of selected informal sectors such as Iron welding and fabricating, sachet and table water plants, milk and fruit juice plant. A copy of questionnaire is attached. Interviewed: Personal interview or face to face interview was conducted from the owners and some workers of the sectors used as sampling in some circumstance that that the question in the questionnaire needs more explanation or clarified for better understanding. This was to use to supplicate that are not in questionnaire but of great assistance to the study. The secondary source of data: Previous researchers analysed and collated Journals, seminar papers and Project work

\subsection{Sampling Techniques}

The sampling technique used is simple random technique. A simple random sample is a subset of a statistical population in which each member of the subset has an equal probability of being chosen. Moore, David S. and George P. McCabe (2006) defines a Simple random sample (SRS) of size $n$ consists of $n$ individuals from the population chosen in such a way that every set of $\mathrm{n}$ individuals has an equal chance to be the sample actually selected."

The SRS was used in selecting respondent from the 3 productive sub informal sector selected for the study because simple random sample is meant to be an unbiased representation of a group. It is considered a fair way to select a sample from a larger population, since every member of the population has an equal chance of getting selected. 


\subsection{Method of Data Collection}

Method use in this study is structured questionnaire. The questionnaire was designed in such a way that the respondent can answer without the presence of researcher. It comprises of two sections $A$ and $B$, section $A$ is a brief profile of respondents while section $B$ of the questionnaire sought the views of respondents on the subject of the study. Then the researcher made use of interviewed and also on already collated, analysed papers related to the study.

\subsection{Method of Data Analysis}

Descriptive and quantitative methods were used to analyse the data obtained. According to Neumann (2008) descriptive research presents a picture of the specific details of a situation, social setting or relationship and uses most data gathering technique, which is surveys, field research, content analysis and historical comparative research. The descriptive method used for this study includes frequency tables, percentages and charts.

\section{DATA ANALYSIS, FINDINGS AND DISCUSSIONS}

\subsection{Data Analysis}

The study assessment in the productivity and coping strategies on Power dependant informal sector in a recessed economy. This chapter focuses on the analysis of data collected based on information received from respondents. The analysis of the data collected was treated on the basis of the research questions and research objectives discusses in chapter one of the study. The questionnaire was distributed within the production sub sector, comprises the iron welding and fabricating, sachet and bottle water and juice and milk plant.

\section{Section A: Demographic Data}

Table 1 Gender of respondent

\begin{tabular}{|l|l|l|l|l|}
\hline Gender & Frequency & Percentage & Valid percent & $\begin{array}{l}\text { Cumulative } \\
\text { percent }\end{array}$ \\
\hline Male & 46 & 92 & 92 & 92 \\
\hline Female & 4 & 8 & 8 & 100 \\
\hline Total & 50 & 100 & & \\
\hline
\end{tabular}

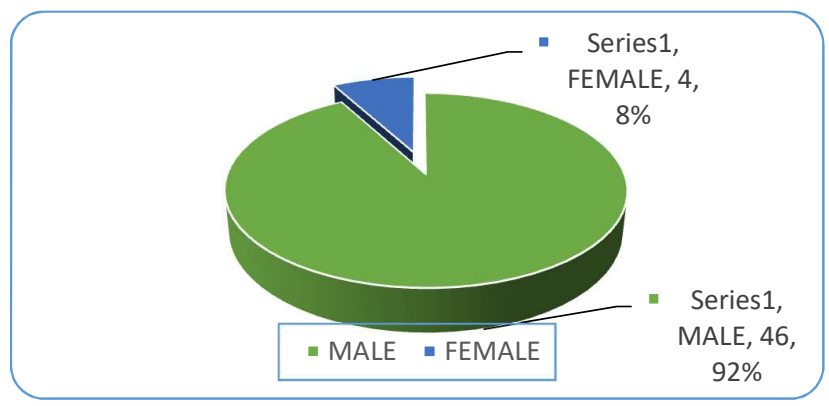

Fig.1 Pie chart showing Gender of the respondent.

Table 1 and chart reveal that out 50 respondents who answered the questionnaire 46(92\%) are male and only $4(8 \%)$. We have larger male than female among the respondent the production sector use for the study are mostly own and control by male. The Iron welding or fabricating has no single female practising the sector as well as the juice and milk plant 4 female respondent was fond among the Sachet and bottle water sector. 
Table 2 Years of experience of respondent

\begin{tabular}{|l|l|l|l|l|}
\hline Years & Frequency & Percentage & Valid percent & Cumulative frequent \\
\hline $0-5$ & 16 & 32 & 32 & 32 \\
\hline $6-10$ & 8 & 16 & 16 & 48 \\
\hline $11-15$ & 13 & 26 & 26 & 74 \\
\hline $16-20$ & 7 & 14 & 14 & 88 \\
\hline $20-$ Above & 6 & 12 & 12 & 100 \\
\hline TOTAL & 50 & 100 & 100 & \\
\hline
\end{tabular}

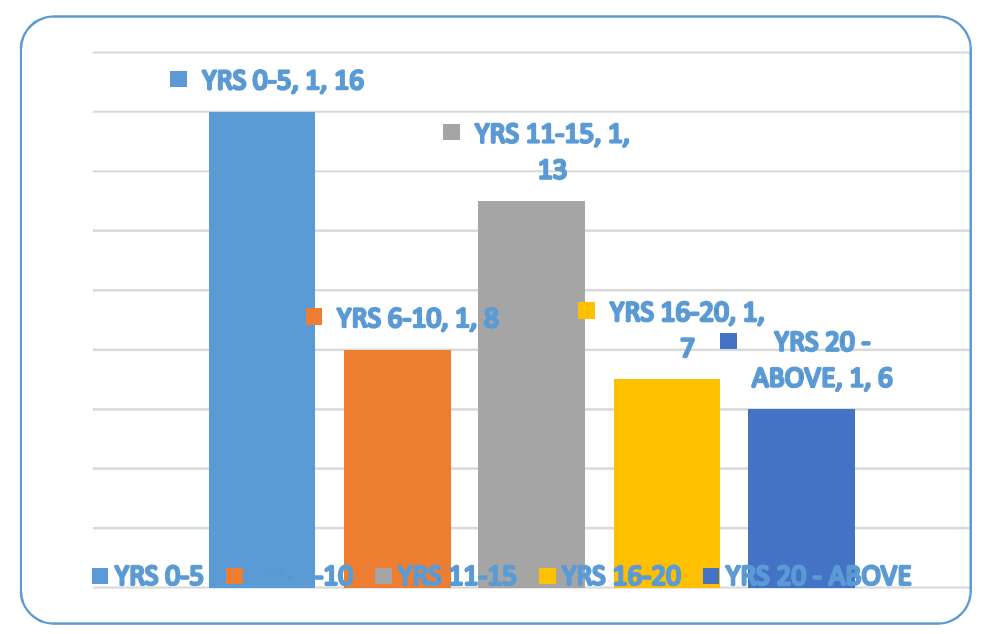

Fig.2 Pie chart showing Years of experience of respondent.

Table 2 and chart shows respondent years of experience, the 0-5 years have the highest frequency; those that have stay longer in the systems struggle along to survive because power supply is a major determinant in surviving.

Table 3 sections of production sector of the respondent

\begin{tabular}{|l|l|l|l|l|}
\hline & Frequency & Percentage & Valid percent & $\begin{array}{l}\text { Cumulative } \\
\text { frequency }\end{array}$ \\
\hline Iron welding or fabricating & 25 & 50 & 50 & 50 \\
\hline Sachet and bottle water & 20 & 40 & \multicolumn{1}{|c|}{40} & 90 \\
\hline Juice and milk plant & 5 & 10 & 10 & 100 \\
\hline Total & 50 & 100 & 100 & \\
\hline
\end{tabular}




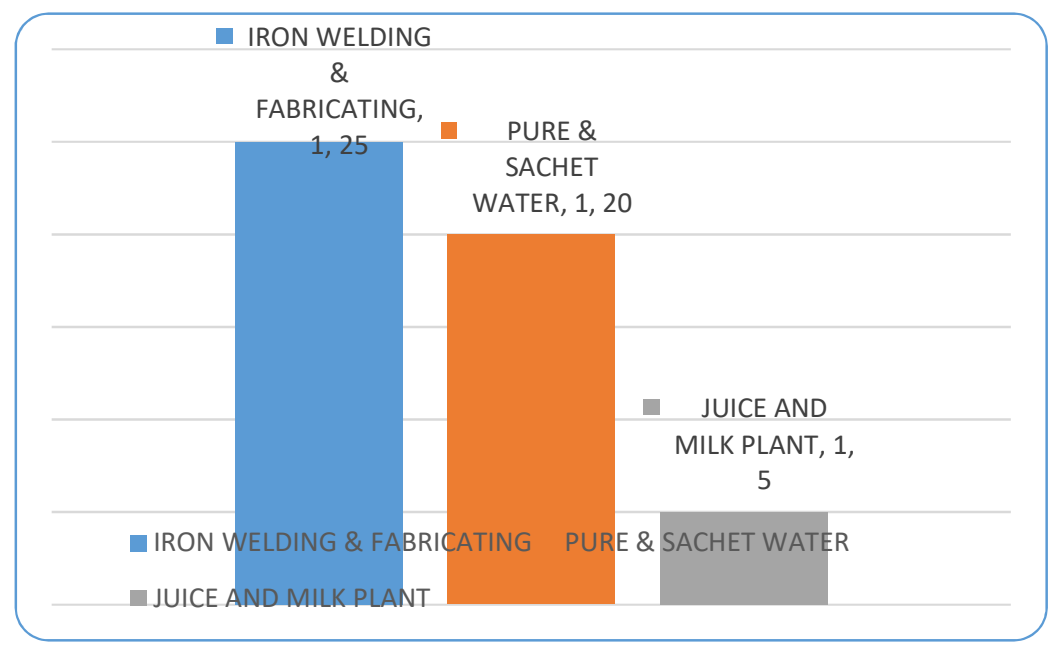

Fig.3 Bar chart showing sections of production sector of the respondent

Table 3 and charts shows how the questionnaire was distributed among the sectors, the iron welding and fabricating was given the larger number because they have the larger percentage in the entire population among the informal sector in the community

\section{Section B}

Table 4: How is the electricity supply in respondent factory area?

\begin{tabular}{|l|l|l|}
\hline & Frequency & Percentage \\
\hline Excellent & 1 & 2 \\
\hline Good & 3 & 6 \\
\hline Better & 13 & 26 \\
\hline Bad & 33 & 66 \\
\hline Total & 50 & 100 \\
\hline
\end{tabular}

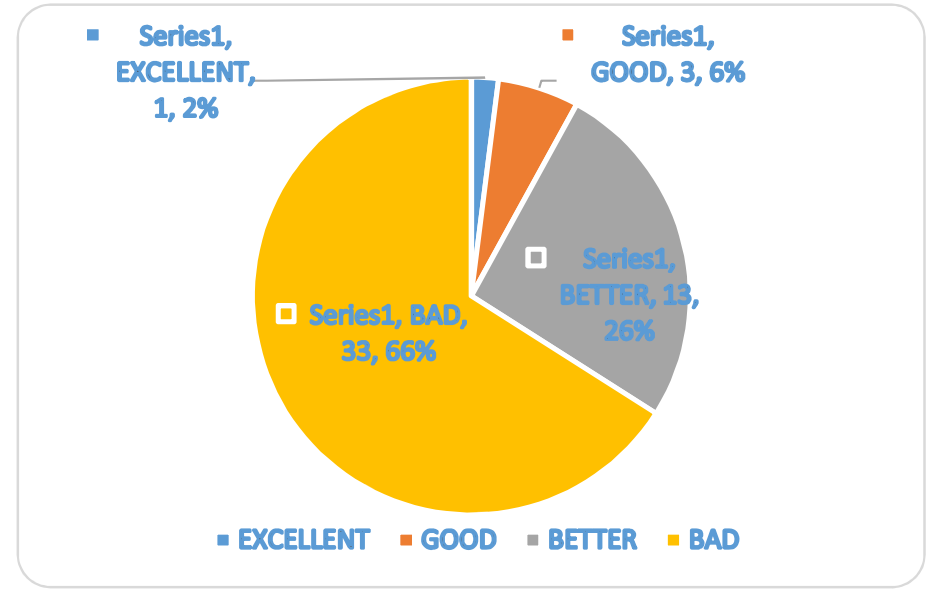

Fig.4 Pie chart showing how is the electricity supply in respondent factory area? 
Table 4 and charts 4 shows that $1(2 \%)$ of the respondent rated the electricity supply in their factory area as excellent, while $3(6 \%)$ rated it good, $13(26 \%)$ rated it better, $33(66 \%)$ rated the supply bad in their factory area. The findings show that the supply of electricity is bad because those that rated it bad have the highest frequency. It really reflects the rate at which the poor supply of power is affecting the factories.

Table 5: How reliable is power supply in factory area

\begin{tabular}{|l|l|l|}
\hline & Frequency & Percentage \\
\hline Very reliable & 0 & 0 \\
\hline Reliable & 1 & 2 \\
\hline Fairly reliable & 16 & 32 \\
\hline Not reliable & 33 & 66 \\
\hline Total & 50 & 100 \\
\hline
\end{tabular}

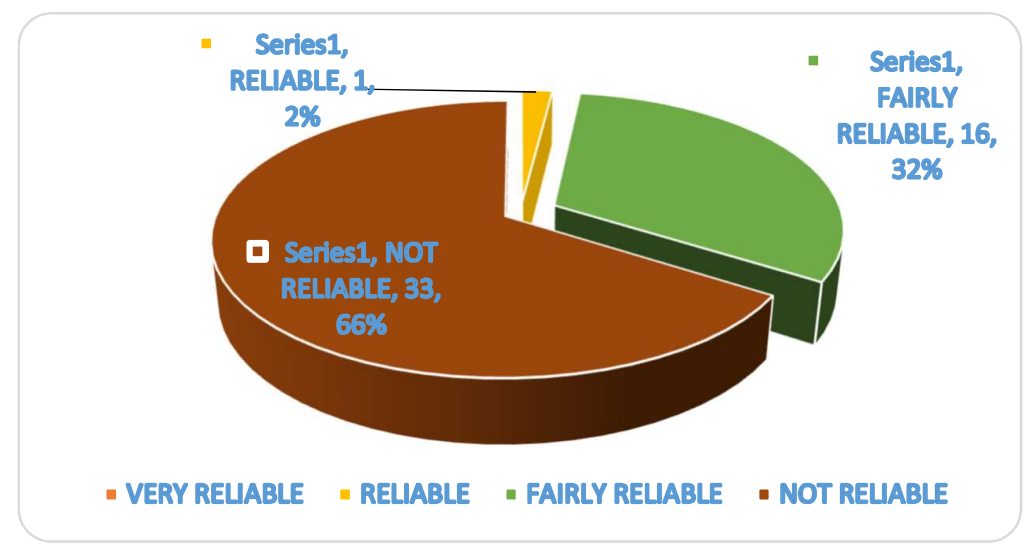

Fig.5: Pie showing how reliable is power supply in their factory area.

Table 5 and chart reflects how reliable is power supply in respondents factory area, no respondent said the supply was very reliable, $1(2 \%)$ responded that is reliable, $16(32 \%)$ responded that it was fairly reliable but majority of respondents says it not reliable which constitutes $33(66 \%)$ of the total respondent. Reliability is different from supply; there might be constant supply of power but might not reliable when the lasting period of its stability is low. From the results power supply is not reliable and it affects the productivity of the informal sectors.

Table 6: How power supply affect productivity

\begin{tabular}{|l|l|l|}
\hline & FREQUENCY & PERCENTAGE \\
\hline Positively & 0 & 0 \\
\hline Fairly positive & 6 & 12 \\
\hline Fairly negative & 19 & 38 \\
\hline Negatively & 25 & 50 \\
\hline Total & 50 & 100 \\
\hline
\end{tabular}




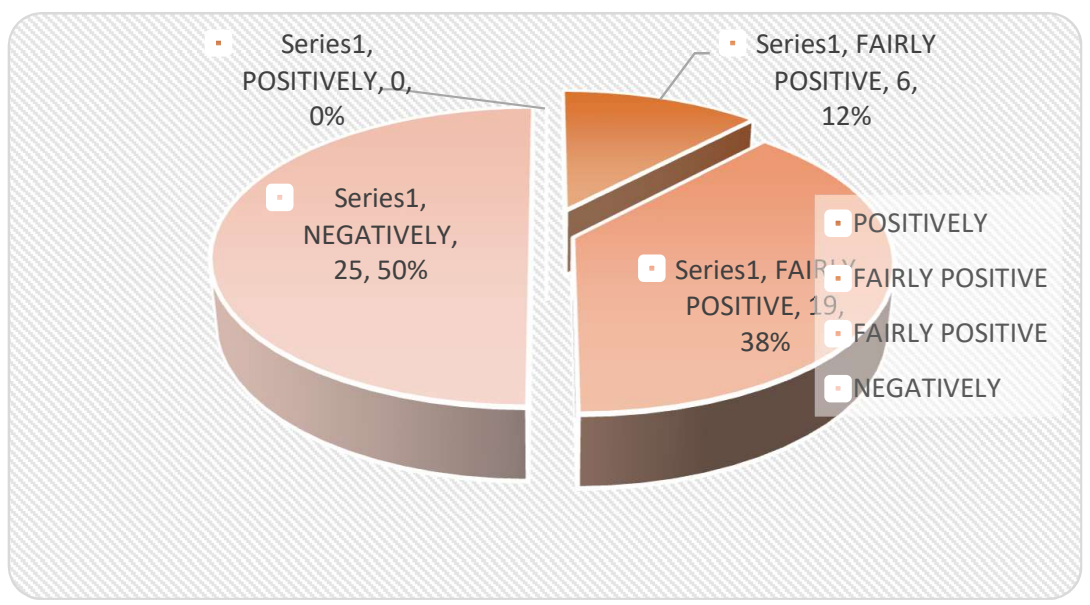

Fig.6 Bar chart showing how power supply affects productivity

Table 6 and charts shows that majorly the supply of power affect productivity negatively, the results shows $25(50 \%)$ which is half of the respondent choose the negatively and followed by $19(38 \%)$ of the respondents that choose fairly negative. The findings of the study revealed that informal sector productivity are majorly affected by power supply.

Table 7: Alternative source of power supply in their factory

\begin{tabular}{|l|l|l|}
\hline & Frequency & Percentage \\
\hline Generator & 48 & 96 \\
\hline Inverter & 1 & 2 \\
\hline Solar & 1 & 2 \\
\hline Total & 50 & 100 \\
\hline
\end{tabular}

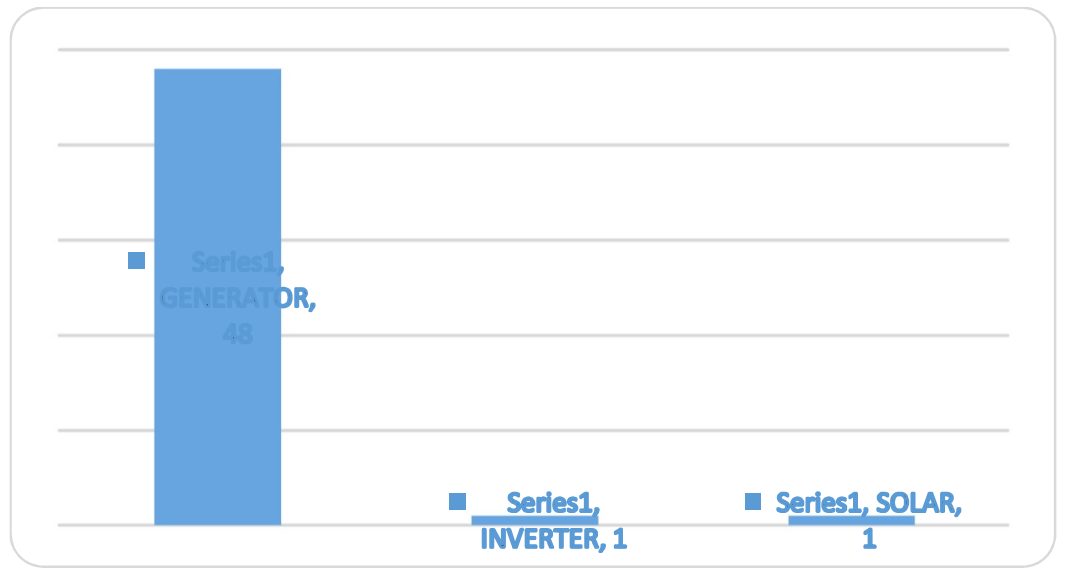

Fig.7 Bar chart showing respondent alternative Source of power supply

Table 7 and chart shows that $48(96 \%)$ respondent uses generator as alternative to power supply, this findings shows that for power dependant informal sector productivity majorly depend on stable supply of power and since they can't have that they all result to generator to power their electricity supply for proper productivity. 
Table 8: How they raise cost of alternative Source of power supply

\begin{tabular}{|l|l|l|}
\hline & Frequency & Percentage \\
\hline Very high & & \\
\hline High & 19 & 38 \\
\hline Moderate & 10 & 20 \\
\hline Low & 0 & 0 \\
\hline Total & $\mathbf{5 0}$ & \\
\hline
\end{tabular}

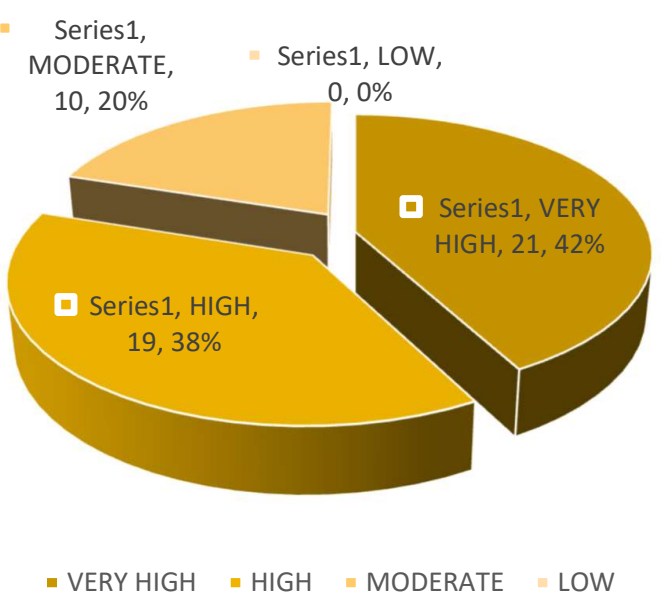

Fig.8 Pie chart showing how respondent rate the cost of alternative to power supply

Table 8 shows that $21(42 \%)$ respondents rate the cost of alternative power supply very high, $19(38 \%)$ respondents rate the cost as high while the remaining $10(20 \%)$ rate the cost as moderate but no respondent rate the cost as low. This shows using alternative power supply is high and will not result in good productivity.

Table 9: How did alternative power supply affect cost of production?

\begin{tabular}{|l|l|l|}
\hline & Frequency & Percentage \\
\hline Positively & 0 & 0 \\
\hline Fairly positive & 1 & 2 \\
\hline Fairly negative & 21 & 42 \\
\hline Negative & 28 & 56 \\
\hline Total & 50 & 100 \\
\hline
\end{tabular}




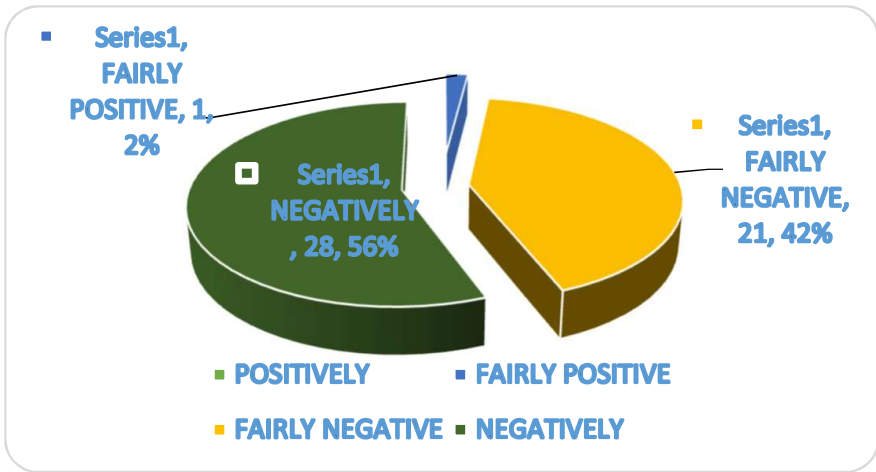

Fig.9 Pie chart showing respondent view how alternative power supply affects their cost of production.

Table 9 shows 28(56\%) respondent said alternative power supply affect their cost of production negatively, $21(42 \%)$ rated it fairly negative and only one respondent rated it fairly positive, this shows that cost of alternative power supply affect production negatively, the cost of alternative power supply is high so it makes cost of production high.

Table 10: Did the respondent agree that their factory or plant is contributing to economic development or growth of the community.

\begin{tabular}{|l|l|l|}
\hline & Frequency & Percentage \\
\hline Strongly agree & 30 & 60 \\
\hline Agree & 16 & 32 \\
\hline Disagree & 3 & 6 \\
\hline Strongly disagree & 1 & 2 \\
\hline Total & 50 & 100 \\
\hline
\end{tabular}




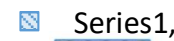
STRONGLY

AGREE, 30
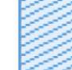

e
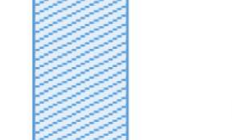

จ Series1,

AGREED, 16

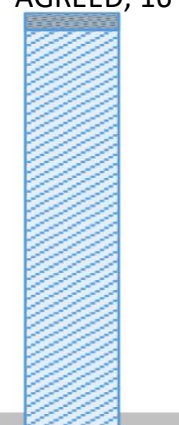

⿴囗S Series1, DISAGREE, 3

¿ Series1, STRONGLY DISAGREE, 1

Fig. 10 Bar chart showing respondent view if their plant or factory contributes to economic growth of the community.

Table $1030(60 \%)$ of the respondents strongly agree that their factory or plant contribute to economic growth, $16(32 \%)$ of respondents agree to that too. This shows informal sector contributes greatly to economic growth and development of the country and the community in particular.

Table 11: If respondent agree that power sector have challenges they faced.

\begin{tabular}{|l|l|l|}
\hline & Frequency & Percentage \\
\hline Strongly agree & 19 & 38 \\
\hline Agreed & 26 & 52 \\
\hline Disagree & 5 & 10 \\
\hline Strongly disagree & 0 & 0 \\
\hline Total & 50 & 100 \\
\hline
\end{tabular}




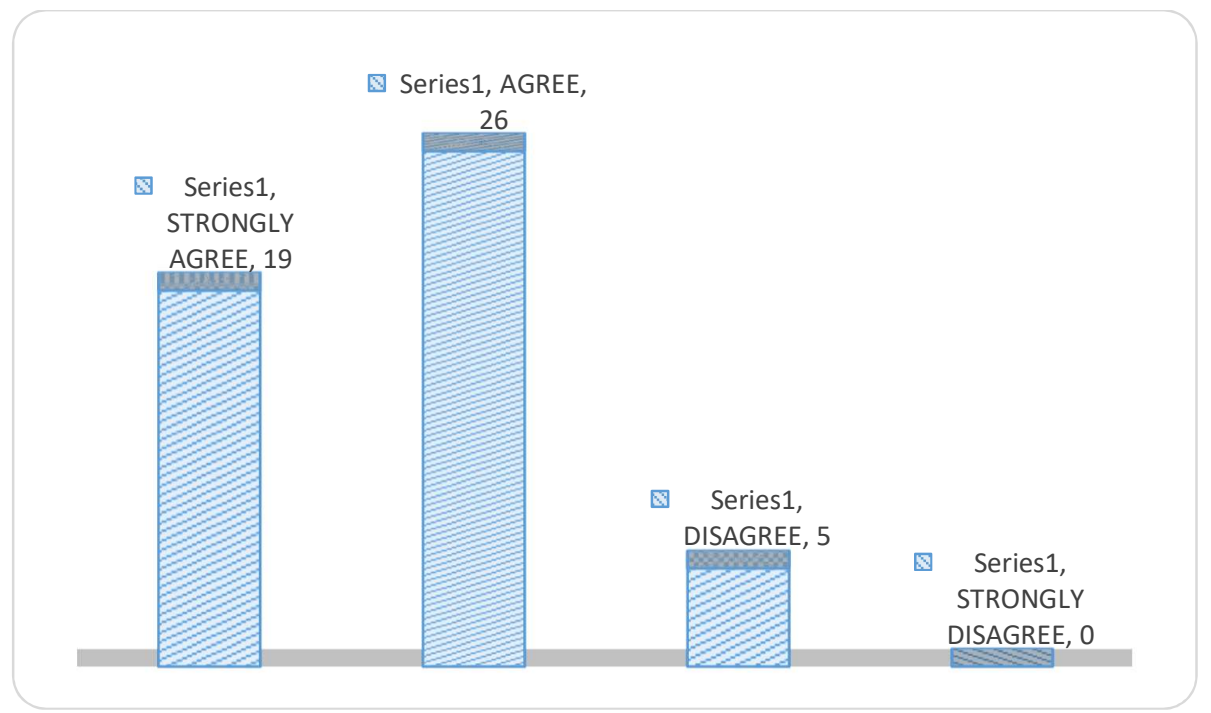

Fig.11 Bar chart showing respondent view on if they agree that power sector have challenges they faced.

The result above revealed that $19(38 \%)$ of the respondents strongly agree that power sector have challenges the faced, however $26(52 \%)$ being a greater percentage of the respondents, supported the view that power sector have challenges they faced. From the result above it can be seen that majority of the respondent agree that power sector have challenges they faced.

Table 12 did respondent agree that the challenges they faced affect their output

\begin{tabular}{|l|l|l|}
\hline & Frequency & Percentage \\
\hline Strongly agree & 20 & 40 \\
\hline Agreed & 25 & 50 \\
\hline Disagree & 5 & 10 \\
\hline Strongly disagree & 0 & 0 \\
\hline Total & 50 & 10 \\
\hline
\end{tabular}




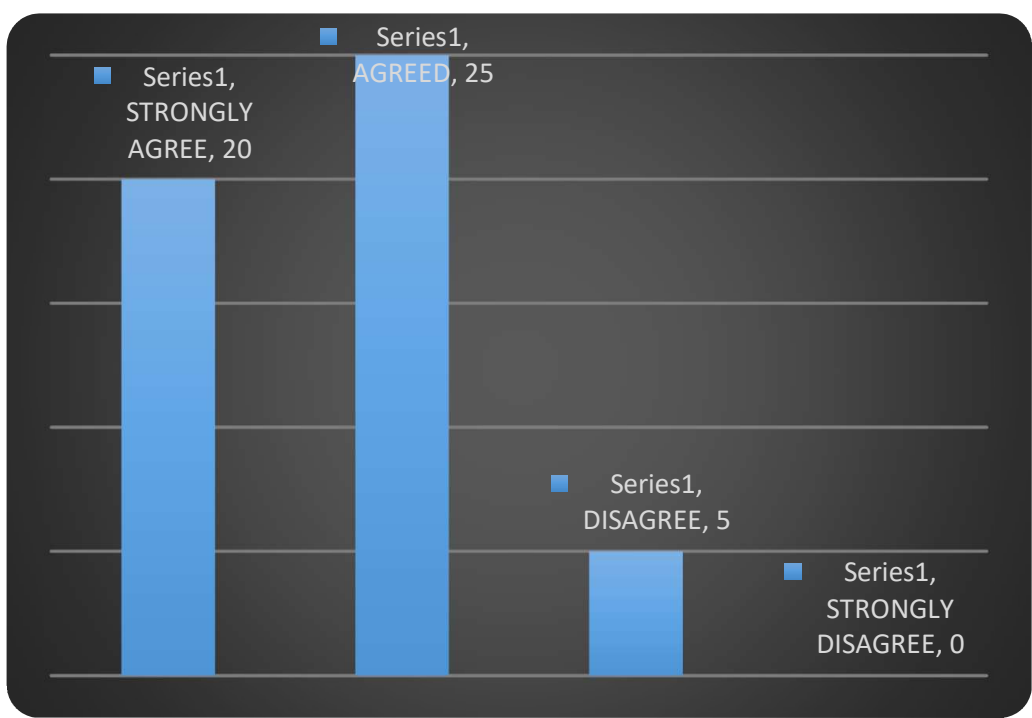

Fig.12 Bar chart showing respondent view on if challenges faced by power sector affect their output.

The result above revealed that $20(40 \%)$ of respondents strongly agree that challenges faced by power sector affect their productivity and $25(50 \%)$ of respondents agreed that to that, this has larger frequency and it shows that Nigerians realised that challenges faced by powers sector affect their output.

Table 13: How does recessed economy affect respondent productivity?

\begin{tabular}{|l|l|l|}
\hline & Frequency & Percentage \\
\hline Positively & 1 & 2 \\
\hline Fairly positive & 2 & 4 \\
\hline Fairly negative & 22 & 44 \\
\hline Negatively & 25 & 50 \\
\hline Total & 50 & 100 \\
\hline
\end{tabular}

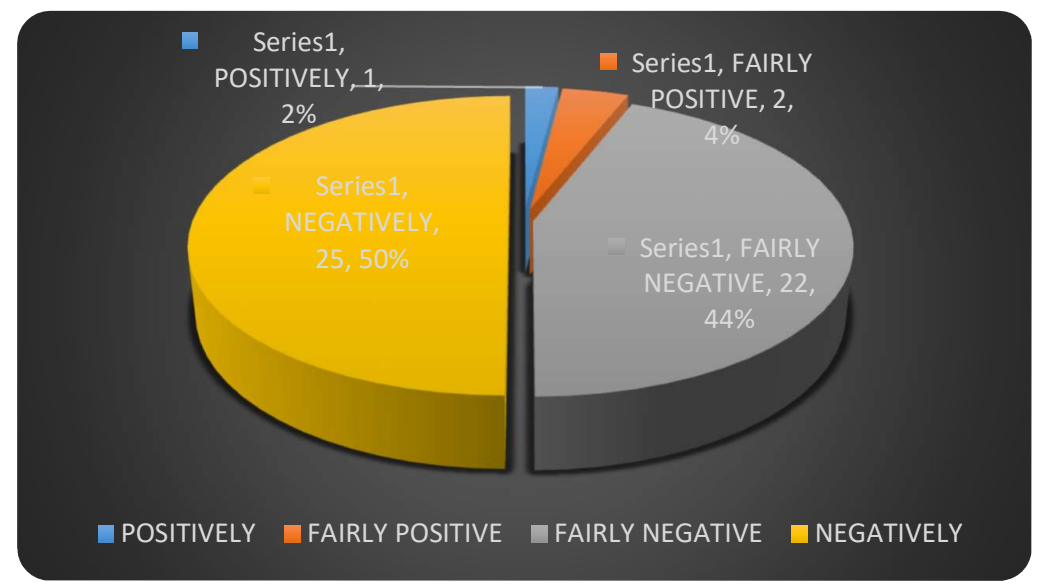

Fig.13 Pie chart showing how does recessed economy affect respondent productivity. 
Table 14: Is the failure in power supply or power outage the major challenges faced in your factory.

\begin{tabular}{|l|l|l|}
\hline & Frequency & Percentage \\
\hline Yes & 40 & 80 \\
\hline No & 3 & 6 \\
\hline Can't tell & 7 & 14 \\
\hline Total & 50 & 100 \\
\hline
\end{tabular}

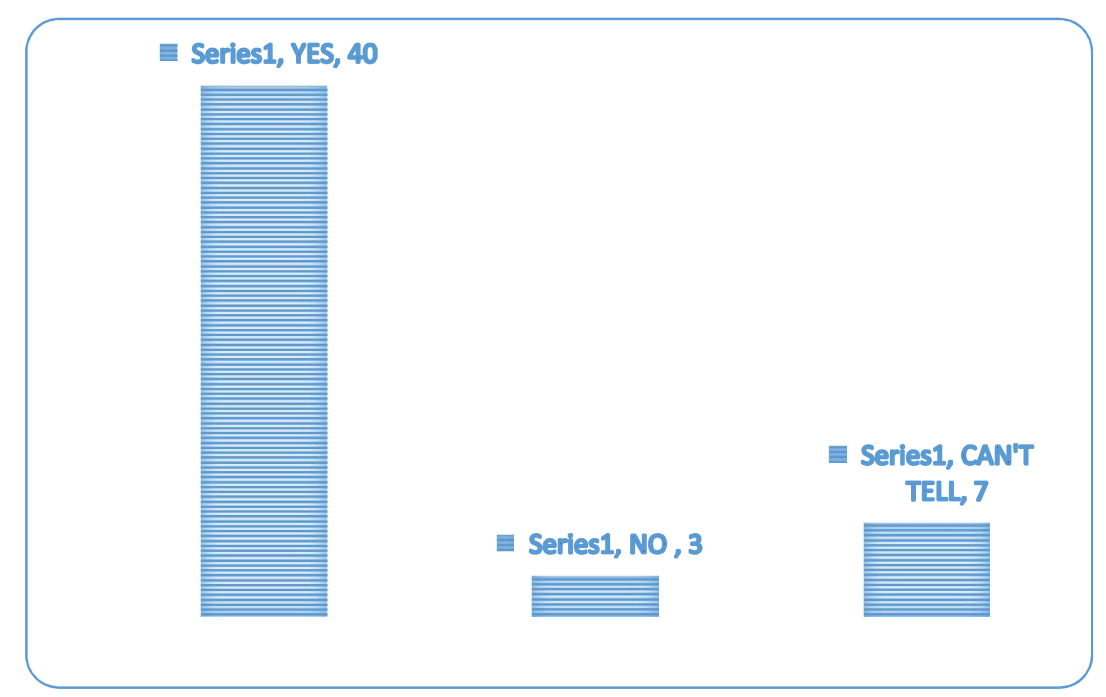

Fig.14 Bar chart showing respondent view if the failure in power supply or power outage is the major challenges faced in their factory.

Table 14 shows that $7(14 \%)$ of respondent chooses can't tell, $3(6 \%)$ of respondents choose No, however $40(80 \%)$ of respondent choose yes that power supply is the major challenges faced by their sector, this accounted for majority of the respondents and which means power supply or power outages have a very significant role in productivity of informal sector in Nigeria. 
Table 15: Did you agree that if electricity supply is stable, is it the best source of power.

\begin{tabular}{|l|l|l|}
\hline & Frequency & Percentage \\
\hline Strongly agree & 33 & 66 \\
\hline Agreed & 16 & 32 \\
\hline Disagree & 0 & 0 \\
\hline Strongly disagree & 1 & 1 \\
\hline Total & 50 & 100 \\
\hline
\end{tabular}

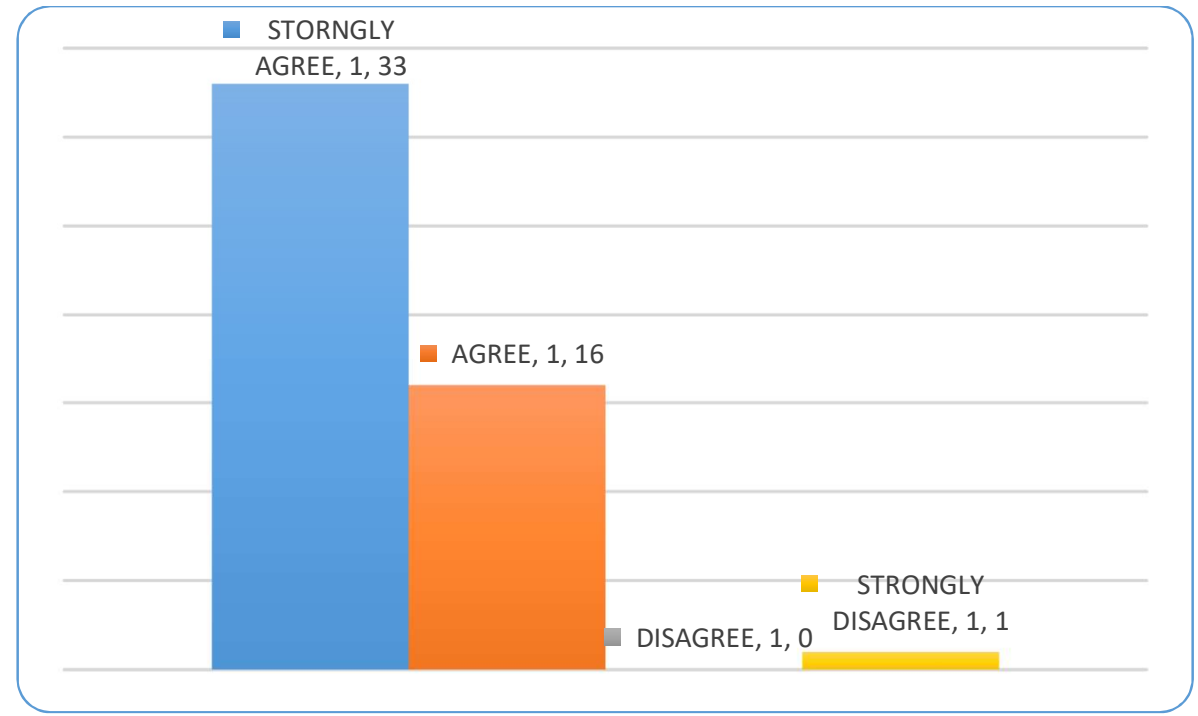

Fig.15 Bar chart showing respondent view if electricity supply is stable is it the best source of power supply.

Table 15 revealed that $33(66 \%)$ of the respondents strongly agree with another $16(32 \%)$ of the respondents agreeing that if electricity supply is stable, it is the best source of power supply for productivity. Therefore from findings it can be inferred from the opinion of the respondents that power supply is a major determinant in all informal sector productivity. 


\section{FINDINGS FROM THE STUDY}

The objective of study is to assess the productivity and coping strategies of power dependant informal sector in a recessed economy. Firstly to examine how power affect the productivity of informal sector. The results shows that out of $33(66 \%)$ out of 50 respondents are of opinion that power supply was very bad, $13(26 \%)$ of respondents are of opinion that the supply was better, also same no of respondent $33(66 \%)$ are of pinion that supply of power are not reliable. The findings shows power supply was very bad and not reliable for use in production process at times if supply was bad but reliable whenever you have it makes it to be useful for production but with this finding it shows the supply is not reliable for use in sectors. This revealed that the power supply that was bad and not reliable is really affecting effective production of power dependant informal sectors. To buttress this point $25(50 \%)$ and $19(38 \%)$ of respondent also are of opinion that failure in power supply or power outages affect productivity negatively and fairly negative respectively. Majority of Informal sector depends on power sector for production. With the problem of power outages and supply it is really a great Problem for most of the informal sectors to survive. For them to be able to survive or cope with the situation they results in alternative means of power supply.

This findings also reveal the coping strategies use by informal sector, the coping strategies use is the alternative power supply and the study shows that $48(96 \%)$ of respondents choose generator as their alternative power supply. The researcher move further to know if the alternative power supply use has any effect on their production or if it is same or even better than regular power supply. 21(42\%) and 19(38\%) of respondents rated the cost of alternative power supply as very high and high respectively. This shows to power their generator is very costly, the use of petrol or diesel is very expensive. The findings shows regular power supply is incomparable to others for effective production of informal sector.

Furthermore, the study also reveal how alternative power supply affect sectors cost of production, 28(56\%) and $21(42 \%)$ of respondents rated it negatively and fairly negative respectively this buttress the point that alternative power supply is costly it add to their cost of production which reduces their productivity. The researcher move further to examine if power sector problem is the major challenges faced by informal sector $44(88 \%)$ respondent out of 50 answered yes, $3(6 \%)$ said no and $7(14 \%)$ are of opinion can't tell, the highest frequency agreed that the major challenges faced by informal sector is power supply or power outages.

The study also revealed that if power supply is stable and reliable, is it the best source of power for use? Strongly agree to the opinion are $33(66 \%)$ and agree to it also is $16(32 \%)$, addition of 33 and 16 gives 49 out of 50 respondents. This shows that power supply plays a very significant role in the productivity of informal sector. Though power sector also wish to serve the country better but they have challenges that is affecting their output. The study shows $19(38 \%)$ of respondents strongly agree that power sectors have challenges they faced, agree to the opinion is $26(52 \%)$ of respondent. Minority of the respondent are of different opinion. $20(40 \%)$ and $25(50 \%)$ are of respondents strongly agree and agree respectively to the opinion that challenges faced by power sector affect their productivity. So if power sector were properly manage by government and their challenges were resolved it will bring out best of output and thus result to best of productivity.

Informal sectors are not just factory or plant for profit making only, they contribute greatly to socio economic growth and development of the country, agree $30(60 \%)$ and agree $16(32 \%)$ to if their plant or factory contribute to economic growth and development of the country and community. Though asides from power sector issues and others, even despite informal sector contribution to the country economy, recessed economy affect everybody in the country including sectors and organization. To buttress this point respondent view on how recessed economy affect productivity, 25(50\%) says recessed economy affect productivity negatively while $22(44 \%)$ choose fairly negative, we only 6 out of 50 respondent falls between positively and fairly positive. This shows that recessed economy affect productivity negatively. Not only productivity, recessed economy affects the general wellbeing of the country citizenry. 


\subsection{Discussion of Findings}

This study was evaluated through the use of questionnaire with questions tailored towards assessment of productivity and coping strategies of power dependant informal sector in recessed economy. To evaluate the socio economic effect of power failure or power outages on productivity of informal sector, to examine the coping strategies and impact of recessed economy on productivity of the sectors. Based on opinion of respondents it can be inferred that power has a negative effect on productivity of informal sector. Also it is the opinion of majority that the interruptible power supply is the major challenge faced by informal sector.

The studies also revealed that majority of informal sector are sole dependant on power as means of surviving. It was also revealed in the study that majority of respondents use generator as their alternative to power supply which means generator is the coping strategies use, and the strategies is affecting their productivity negatively because to power their generator is very expensive. Majority of respondents admit that power sector too faced challenges that affect their output. Lastly the study revealed that recessed economy have a very negative effect on productivity.

Based on the result of the study the researcher's opinion is all informal sector especially the productive sub informal sector basically depends on power for production, however the power supply is not adequate for the required consumption also the effect of recessed economy is not left out. Despites the contribution of informal sector to the nation's economic growth and development.

\section{CONCLUSIONS}

This study reveals that informal sector in Nigerian are exposed to issues that affect their productivity. The major issue revealed in this study is the impact of power supply or power outage on informal sector productivity. The findings shows that informal productive sector depends mainly on power for operations which inferred that there is a positive relationship between informal sectors and the power sector in terms of their total output. The research revealed that sectors employ use of alternative power supply for production but it also affect their productivity negatively due to high cost financing their generator which increases their cost of production their by reduces productivity

However the findings shows power sector faces some challenges that affect their output too. It was also revealed in the study that recessed economy affect the informal sector productivity negatively. Though it was revealed that informal sector have positive contribution to country economic growth and development. Informal sector are mostly establish for profit making, but mostly they play dual role because they provide profit for the owners and contribute to nation's economy. They serve as National development; enhance job creation and technological innovation. They also enhance capacity building, provide feeder industry services and provide opportunities for the development of local skills. Despite all the positive contribution of informal sector to the nation; they still faced challenges that leads most of informal sector to premature death or under productive.

In view of the above to increase the productivity of informal sector so as to achieve all their contribution to the country economy the government should see to problems faced by sectors to ensure they have smooth operation that will result to higher performance. The problem faced is majorly from power sector, therefore adequate monitoring and financing of this sector is important if any meaningful results are to be achieved. Hence the performance of informal sector greatly depends on quality and availability of adequate power supply in Nigeria. Arising from the findings from the analysis using Microsoft excel to analyse, the study concludes that there is a very significant relationship between the productive informal sector and the power sector. 


\section{RECOMMENDATIONS}

Based on results obtained from the study the following recommendations have been made to put more impress on increase the output level of power sector because it serves as a major determinant of informal sector productivity.

* Government should see to problems of power sector like major breakdown arising with use of outdate equipment, lack of maintenance culture, inadequate generation due to operational/ technical problems.

* Government should provide proper funding for power sector, if funded regularly and properly it will take care of most the issues affecting power sector output.

* Government should provide proper monitoring team for power sector to cultivate proper maintenance culture.

Aside from above mention recommendations mainly on power sector this are other recommendations to improve informal sector productivity.

* Government should provide proper funding like guarantee of long term, medium and short term loan for sector to enhance their operations since they contribute to nation's building.

* Government should intensify their efforts in tackling other challenges of informal sector as this will make more resources available for treating problems confronting informal sector.

* Informal sectors owners should try to inculcate the culture of corporate governance.

- Also government should place increasing attention on policy that can promote effective organization of informal sector enterprise.

* Provision of tax incentives for informal sector operators to encourage informal sectors owners.

* To achieve sustainable development goals government should inaugurates informal sector monitoring group.

\subsection{Proposal for Further Studies}

Further research should expand on this study in other to improve on the study for the benefit of Academia. Future research could be conducted for usefulness of the regulatory body monitoring both the informal sector and power sector for knowledge on problems needs and solution. Future research should carried out expatiate more on the topic for benefit of stakeholders. 


\section{BIBLIOGRAPHY}

1. Ahmadou Aly Mbaye (2014): The Informal Sector, Employment and Structural Transformation.

2. Busani Moyo (2012): Do power cuts affect Productivity? A case study of Nigerian manufacturing Firms; International Business and Economics Research Journal.

3. Carlos Pestana Barros Et al (2011) Nigeria Power Sector: Analysis of Productivity

4. Dr Akiri Et al (2015) Electricity supply and the manufacturing productivity in Nigeria; IOSR Journal of Economics and Finance, Volume 6 PP 90-94

5. Dr Mba Okechukwu Agwu and Dr Cletus Izunwanne Emeti (2014) Issues, Challenges and Prospects of small and medium scale enterprises (SMEs) in Port-Harcourt city, Nigeria; European Journal of sustainable development.

6. Emmanuel Noko (2016): Impact of power supply failure in Nigeria economy 1981 - 2015; EduCacInfo.com

7. European journal of business and social sciences volume 2 No 9 page 76 -94 (2013) SMES Business risks and sustainable in Nigeria.

8. Gbadebo, Olusegun Odularu and Chinedu Okonkwo (July 2009) Does energy consumption contribute to economic performance? Empirical evidence from Nigeria Journal of Economics and International Finance Vol. 1(2), pp. 044-058

9. Harnessing the Potentials of the Informal Sector for Sustainable Development - Lessons from Nigeria Joseph O. Dada

10. I A H Ekpo and O J Umoh (2013): The informal sector; an overview of Nigerian growth and development posted by web 29/12/2013

11. IDUU GLORIA (2012) Power supply and the performance of small and medium scale industries in Nigeria $(1986$ - 2012)

12. Ismail O. Fasanya and Adegbemi B.O Onakoya (2012) Informal sector and employment generation in Nigeria; Research on humanities and social sciences Vol 2, No.7.

13. Jonathan Emenike Ogbuabor and Victor A. Malaolu (2013) Size and Causes of the Informal Sector of the Nigerian Economy: Evidence from Error Correction Mimic model; Journal of Economics and Sustainable Development www.iiste.orgVol.4, No.1

14. KPMG in Nigeria (2016) A guide to the Nigeria power sector.

15. Mbunwe and Muncho Josephine (2014) Analysis of Energy Crisis and How it Affects Production Sector and Economic Growth of Nigeria; Proceedings of the World Congress on Engineering and Computer Science Vol I, 22-24 San Francisco, USA

16. Mrs Nwankwo Olivia Chigozie and Dr (Mrs) Njogo, Bibiana Oluchukwu (2013) The Effect of Electricity Supply on Industrial Production within the Nigerian Economy (1970 - 2010); A Journal of Energy Technologies and Policy www.iiste.org Vol.3, No.4.

17. Ogaji Comfort- Asokoro (2011): The importance of energy to the Nigerian economy.

18. Onyemaechi Joseph Onuwe (2013) Role of Informal Sector in development of Nigeria economy; output and employment approach; NOUN A journal of economics and development studies

19. Peter Samuel Ubi Et al (2012) An Econometric Analysis of the Determinants of Electricity Supply in Nigeria; International Journal of Business Administration Vol. 3, No. 4.

20. Tajudeen Olalekan Yusuf and Francis Sewhenu Dansu(2013) SMEs, Business risks and sustainability in Nigeria; European Journal of Business and Social Sciences, Volume 2 No 9 PP 76-94

21. The Nigeria of experience international conference on Arts, Economics and Management (2014): The role of small and medium enterprises in economic development.

22. The Sun Newspaper (28 $8^{\text {th }}$ March 2016 ) How Epileptic Power Supply's killing Nigerian Industries.

23. Udochukwu B Akuru and Ogbonnaya I Okoro (2014) Economic Implications of Constant Power Outages on SMEs in Nigeria; Journal of Energy in Southern Africa Volume 25

24. Ugochukwu .U. Ikeije Et al (2016) Labour practices in the informal sector of Nigerian economy; Global Journal of Arts, Humanities and Social Sciences; Vol.4, No.2, pp. 6-14

25. Yusuf Olabisi Sherifat Et al Factors affecting small scale business performance in informal economy in Lagos state: A gendered based analysis

26. Yusuf Olabisi Sherifat (2011) A theoretical Analysis of the concept of informal economy and informality in developing countries; European journal of social sciences- volume 20 No 4 


\section{APPENDIX}

\section{QUESTIONNAIRE \\ Dear sir or madam}

This questionnaire is part of a thesis research work on assessment of producing and coping strategies of power dependant informal sector in a recessed economy. You have been selected as one of the respondent to participate in this survey through a careful random sampling. I would really appreciate if you could answer the following question. All information provided will be used for the purpose of this research and treated confidentially. All your answers to the question will be regarded as your opinions and hence or correct answers will be deduced from them.

Thank you.

\section{SECTION A DEMOGRAPHIC DATA}

Please kindly complete the following statement by ticking, filling box or space provided.

1. Gender: Male [ ] Female [ ]

2. Position: General Managerial Cadre [ ] Operation Manager [ ] OTHERS Please specify----------$--$

3. Is the factory or plant belongs to you?

$$
\text { Yes [ ] No [ ] }
$$

4. How long have you been working in the establishment 0-5 [ ] 6-10 [ ]11-15 [ ] 16-20 [ ] 20-above [ ]

5. Which part of production is your plant or factory belong to? Iron welding or fabricating [ ] sachet and bottle water [ ] juice and milk plant [ ] others [ ]

6. What is the staff strength of your establishment [ ]

\section{SECTION B: POWER EFFECT AND COPING STRATEGIES OF INFORMAL SECTOR IN RECESSED ECONOMY}

1. How is the electricity supply in your factory area? Excellent [ ] Good [ ] Better [ ]Bad [ ]

2. How frequent is power supply for your production? Frequently [ ] Very frequent [ ] fairly frequent [ ] Not frequent [ ]

3. Is Electricity a major source of power supply for your production? Strongly agreed [ ] agreed [ ] disagreed [ ] strongly disagreed [ ]

4. How reliable is power supply in your factory area? Very reliable [ ] reliable [ ] fairly reliable [ ] not reliable [ ]

5. How does power supply affect productivity? Positively [ ] fairly positive [ ] fairly negative [ ] negatively [ ]

6. What is your alternative source of power supply in your factory? Generator [ ] inverter [ ] solar [ ]

7. How would you raise the cost of alternative power supply? Very high [ ] high [ ] moderate [ ] low [ ]

8. How did alternative power supply affect your cost of production? Positively [ ] fairly positive [ ] fairly negative [ ] negatively [ ]

9. Did your plant or factory contribute to the development or economic growth of the community? Strongly agreed [ ] agreed [ ] disagreed [ ] strongly disagreed [ ]

10. Did you agree that power sector have challenges they faced? Strongly agreed [ ] agreed [ ] disagreed [ ] strongly disagreed [ ]

11. Did you agree that their challenges affect their output? Strongly agreed [ ] agreed [ ] disagreed [ ] strongly disagreed [ ]

12. How does recessed economy affect productivity? Positively [ ] fairly positive [ ] fairly negative [ ] negatively [ ]

13. Is the failure in power supply or power outage the major challenges faced by your factory? Yes [ ] no [ ] can't tell [ ]

14. Did you agree that if electricity supply is stable, is the best source of power supply? Strongly agreed [ ] agreed [ ] disagree [ ] strongly disagree [ ] 